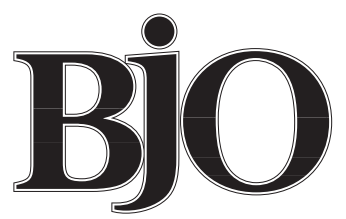

British Journal of Ophthalmology

\title{
Editorials
}

\section{Blood flow in the Zinn-Haller circle}

Disturbance of posterior ciliary arterial circulation is primarily responsible for common ischaemic disorders of the optic nerve head $(\mathrm{ONH})$ such as anterior ischaemic optic neuropathy and glaucomatous optic neuropathy. ${ }^{1}$ Much of the attention given to the vasculature of the $\mathrm{ONH}$ stems from an interest in these conditions. Anatomical studies using vascular casts or serial histological sections and angiography have provided a basis for understanding blood supply but, because the feeding arteries could not be visualised hitherto, knowledge of the vascular dynamics remained uncertain. Moreover, disagreements on vascular structure persist; two examples concern the roles of the Zinn-Haller circle and the choroidal arteries. Accepting that $\mathrm{ONH}$ blood supply is substantially centripetal and derived from the short posterior ciliary arteries (SPCAs), to what extent does the Zinn-Haller circle function as an intermediary? In the recent past some observers reported the circle to be incomplete or commonly absent and claimed that direct centripetal branches from SPCAs provide the lamina cribrosa blood supply. ${ }^{2}{ }^{3}$ Now, the weight of evidence, obtained mainly from cast studies, indicates that it is regularly present with medial and lateral SPCAs or their branches turning within the plane of the peripapillary sclera to run in an arcuate fashion. They anastomose, forming a complete circle in a majority of eyes and arterioles issue at intervals from the circle passing centripetally to the laminar $\mathrm{ONH}$, possibly also to the prelaminar $\mathrm{ONH}$ or as pial arterioles to the post-laminar ONH..$^{4-7}$ Regarding the choroidal supply to the $\mathrm{ONH}$, those peripapillary choroidal arteries supplying recurrent branches to the laminar or post-laminar ONH either issue from SPCAs directly $^{1}$ or from the Zinn-Haller circle ${ }^{56}$ but the main debate turns on the question of whether choroidal branches penetrate the border tissue of Jacoby to enter the prelaminar $\mathrm{ONH}^{1}$ or enter from the level of the sclera. ${ }^{4}$

Returning to the first of these problems, if the circle is completed or nearly completed by anastomoses then the ONH vascular supply is not an end arterial system, and potentially a reduction in the perfusion pressure in one of the feeding arteries would be compensated by the contribution from others, avoiding segmental $\mathrm{ONH}$ deficit. But as Hayreh ${ }^{1}$ makes clear, one cannot conclude that a functional connection exists on the evidence of plastic casts of cadaver eyes. In this issue of the $B \mathcal{B O}$ (p 1357) Ohno-Matsui and colleagues report a further development of indocyanine green angiography ${ }^{9}{ }^{10}$ enabling them to visualise the circle fully in myopic eyes with an annular crescent. They find an incomplete Zinn-Haller circle supplied by medial and lateral SPCAs in half of the 44 eyes studied, and only by medial or lateral arteries in others. Anastomotic channels between medial and lateral SPCAs were not observed indicating that the circle functions as an end arterial system. Olver et al, ${ }^{11}$ noting two instances among 18 eyes of a circle supplied by a single SPCA, commented that in such eyes there may be potential vascular vulnerability. Ohno-Matsui and others' results indicate that a unilateral input to the circle is functionally quite common.

Results from highly myopic eyes may not be representative but not withstanding, Ohno-Matsui and colleagues' report is a significant advance in knowledge and it may have some bearing on the development of segmental defects of the $\mathrm{ONH}$.

\section{GORDON RUSKELL}

Department of Optometry and Visual Science, City University, London EC1V 7DD

1 Hayreh SS. The optic nerve head circulation in health and disease. Exp Eye Res 1995;61:259-72.

2 Levitzsky M, Henkind P. Angioarchitecture of the optic nerve. II. Lamina cribrosa. Am f Ophthalmol 1969;68:986-96.

3 Hayreh SS. Blood supply of the optic nerve head in health and disease. In: Lambrou GN, Greve EL, eds. Ocular blood flow in glaucoma. Amsterdam: Kugler and Ghedini, 1989:3-48.

4 Lieberman ME, Maumenee AE, Green WR. Histologic studies of the vasculature of the anterior optic nerve. Am f Ophthalmol 1975;82:405-23.

5 Fryczkowski AW, Grimson BS, Peiffer RL. Scanning electron microscopy of vascular casts of the human lamina cribrosa. Int Ophthalmol 1984;7:95100.

6 Olver JM, Spalton DJ, McCartney ACE. Microvascular study of the retrolaminar optic nerve in man: the possible significance in anterior retrolaminar optic nerve in man: the possib

7 Onda E, Cioffi GA, Bacon DR, van Buskirk EM. Microvasculature of the human optic nerve. Am $\mathcal{f}$ Ophthalmol 1995;120:92-102.

8 Zhao Y, Li F. Microangioarchitecture of the optic papilla. fap f Ophthalmol 1987;31:147-59.

9 Park KH, Tomita G, Onda E, et al. In vivo detection of perineural circular arterial anastomosis (circle of Zinn-Haller) in a patient with large peripaillary chrioretinal atrophy. Am f Ophthalmol 1996;122:905-7.

10 Ohno-Matsui $\mathrm{K}$, Morishima $\mathrm{N}$, Ito $\mathrm{M}$, et al. Indocyanine green fundus angiography of retrobulbar vascular structure in high myopia. $A m \mathcal{F}$ Ophthalmol 1997;123:494-505.

11 Olver JM, Spalton DJ, McCartney ACE. Quantitative morphology of human retrolaminar optic nerve vasculature. Invest Ophthalmol Vis Sci 1994;35:3858-66. 


\section{Ploidy analysis in uveal melanoma}

For uveal melanoma it has been shown that nuclear DNA content (ploidy) abnormalities correlate closely with survival, ${ }^{1-4}$ although conflicting results have been reported for older archival material, ${ }^{5}$ fresh tissue,${ }^{6}$ and differences in DNA quantification techniques. ${ }^{7}$ A significant correlation between aneuploidy and epithelioid cell type has been reported ${ }^{238}$; other studies indicate similar findings, ${ }^{9}$ or contradict these findings. ${ }^{4}$ In this issue of the $B F O(\mathrm{p} \mathrm{1433)}$ Toti et al report conflicting results on the prognostic value of aneuploidy and association of aneuploidy with epithelioid cell type in uveal melanoma. Furthermore, they found a remarkably high incidence of hypodiploidy.

Methods for ploidy analysis include flow cytometry (FCM), static image analysis (IA), and-more recentlythe cytogenetic approach. Each ploidy analysis has its own advantages and disadvantages, many of which reflect the reported conflicting results. ${ }^{10} 11$ Ploidy analysis by FCM and IA has been reported for uveal melanoma. ${ }^{1-9}{ }^{12}{ }^{13}$ Both methods plot the cells at the different stages of the cell cycle on a histogram. FCM is a widely accessible and fast method, quantifying fluorescent nuclear material in suspension, requiring a relatively large sample size $(>5000$ cells). IA measures the quantity of light (pixels) in a Feulgen stained specimen requiring fewer cells (100-500 cells), and is more suitable in detecting rare events. The coefficient of variation (CV), reflecting the width of the peak, hence the accuracy of measurements, is usually larger in IA than in FCM. IA is particularly useful in cell recognition and classification, and measurements of cell components. Comparing IA and FCM on uveal melanomas, tetraploidy was detected in tumours that were diploid by FCM. ${ }^{12}$ By IA it was found that all spindle A cells were diploid, ${ }^{72}$ and most tetraploid peaks were formed by epithelioid cells. ${ }^{12}$ The lack of association of aneuploidy with epithelioid cell type may partly be explained by the application of a modified (five categories) classification (see Toti et al). Simplification (into three categories) has improved histological correlation of uveal melanoma with malignancy, ${ }^{14}$ but is still subject to variations in interpretation.

The principal problems with classification of tumour histograms on FCM occur when the deviation from the normal histogram pattern of controls is subtle. ${ }^{10}$ Near diploid, near tetraploid, and small non-diploid cell populations can be observed in histograms from fresh frozen tissue by FCM, using normal tissue component as the normal counterpart. ${ }^{11}$ When using paraffin embedded material, no samples are classifiable as hypodiploid (DI <0.95), as by definition the first G0/G1 peak appearing in the histogram is considered to be diploid. ${ }^{11}{ }^{15}$ Fixation artefacts may arise particularly in the generation of near diploid DNA aneuploid tumours, but also in the diploid standard. ${ }^{11}$ Because of the above named restrictions, the recommended FCM ploidy classification on paraffin embedded tissue from solid tumours is diploid versus nondiploid (aneuploid). ${ }^{11}$ Conflicting results on the prognostic value of DNA aneuploidy can be attributed to differences in methods $s^{6}$ and definition of aneuploidy (Toti et al). Difficult areas in flow histograms, specifically high CV, high G2M phase, as well as near diploid aneuploidy and hypodiploidy can be clarified by IA, ${ }^{16}$ or in frozen tissue by FCM. ${ }^{11}$

Hypodiploidy has been investigated in IA studies of several solid tumours (frozen tissue and paraffin embedded tissue), ${ }^{17-19}$ and by FCM on frozen tumour tissue. ${ }^{15} 20$
Schilling et $a l^{8}$ performed IA on paraffin embedded irradiated and non-irradiated uveal melanomas. They found hypodiploidy exclusively in irradiated melanomas. This is in sharp contrast with the unusual high percentage of nonirradiated, hypodiploid uveal melanomas reported by Toti et al in this issue. Nevertheless, the aggressive behaviour of hypodiploid tumours is an intriguing concept, because loss of one chromosome may result in a hypodiploid DNA pattern. Interestingly, loss of chromosome 3 is an important prognostic factor in uveal melanoma. ${ }^{21}{ }^{22}$ However, additional copies of chromosome $8 \mathrm{q}$, which have an inverse dosage effect on survival, ${ }^{22}$ may balance this. Furthermore, considerable discrepancies have been found between flow cytometric and cytogenetic studies in the detection of aneuploidy in human solid tumours. ${ }^{23}$

In recent years, fluorescent in situ hybridisation (FISH) has been established as a valuable tool for the detection of the chromosomal aberrations and aneuploidy in a variety of human solid tumours, ${ }^{24}$ including uveal melanoma. ${ }^{25}$ The sensitivity of FISH for the detection of aneuploidy is dependent mainly on the number of analysed chromosomes per specimen. Comparative genomic hybridisation $(\mathrm{CGH})$ is based on dual colour FISH between patient tumour DNA and normal reference DNA, and is applicable on paraffin embedded tissue. CGH on uveal melanoma revealed non-random loss of chromosome 3, gain of $6 p$ and loss of $6 \mathrm{q}$, and gain of $8 \mathrm{q} .{ }^{26}$

In summary, discordant results between the different methods of ploidy analysis, different methods of handling tissue, and technical factors most probably represent intrinsic limitations of the different methods, in addition to intratumour ploidy heterogeneity.

CORNELIA M MOOY

Department of Pathology and Ophthalmology, Erasmus University, Rotterdam

1 Meecham WJ, Char DH. DNA content abnormalities and prognosis in uveal melanoma. Arch Ophthalmol 1986;104:1626-9.

2 Karlsson M, Boeryd B, Carstensen J, et al. DNA ploidy and S-phase fraction as prognostic factors in patients with uveal melanomas. Br F Cancer 1995; 71:177-81

3 Mooy C, Vissers K, Mulder A, et al. DNA flow cytometry in uveal melanoma: the effect of pre-enucleation radiotherapy. $\mathrm{Br} F$ Ophthalmol $1995 ; 79: 174-7$.

4 Hodge WG, Duclos AJ, Rocha G, et al. DNA index and S phase fraction in uveal malignant melanomas. Brf Ophthalmol 1995;79:521-6.

5 McMillan J, Char, DH, McLean IW, et al. DNA content analysis of uveal melanoma. Arch Ophthalmol 1989;107:1278.

6 Richardson RP, Lawry L, Rees RC, et al. DNA index and \% S phase fraction in posterior uveal melanoma: a 5 year prospective study of fresh tissue using flow cytometry. Eye 1997;11:629-34.

7 Coleman K, Baak JPA, van Diest PJ, et al. DNA ploidy status in 84 ocular melanomas: a study of DNA quantitation in ocular melanomas by flow cytometry and automatic and interactive static image analysis. Hum Pathol 1995;26:99-105.

8 Schilling H, Weng Sehu K, Lee WR. A histologic study (including DNA quantification and Ki-67 labeling index) in uveal melanoma after brachytherapy with ruthenium plaques. Invest Ophthalmol Vis Sci 1997;38: brachyther

9 Shapiro BE, Felberg NT, Donoso LA, et al. Flow cytometry of uveal melanoma. Cancer Biochem Biophys 1986;9:235-8.

10 Koss LG, Czerniak B, Herz F, et al. Flow cytometric measurements of DNA and other cell components in human tumors: a critical appraisal. Hum Path 1989;20:528-48.

11 Shankey TV, Rabinovitc PS, Bagwell B, et al. Guidelines for implementation of clinical DNA cytometry. Cytometry 1993;14:472-7.

12 Coleman K, Baak JPH, Dorman A, et al. Deoxyribonucleic acid ploidy studies in choroidal melanomas. Am f Ophthalmol 1993;115:376-83.

13 Rennie IG, Rees RC, Parsons MA, et al. Estimation of DNA content in uveal melanoma by flow cytometry. Eye 1989;3:611-7.

14 McLean IW, Foster WD, Zimmerman LE, et al. Modifications of Callender's classification of uveal melanoma at the Armed Forces Institute of Pathology. Am $\mathcal{F}$ Ophthalmol 1983;96:502-9.

15 Fernö M, Baldetorp B, Borg A, et al. Flow cytometric DNA index and $\mathrm{S}$-phase fraction in breast cancer in relation to other prognostic variables and to clinical outcome. Acta Oncol 1992;31:157-65.

16 Lanigan D, McLean PA, Curran B, et al. Comparison of flow and static image cytometry in the determination of ploidy. F Clin Pathol 1993;46:1359 . 
17 Cohen C, Walker BF, Solomon AR, et al. DNA ploidy and cell cycle analysis in ear malignant melanoma by flow and image cytometry. Anal Quant Cytol Histol 1992;14:81-8.

18 Simony J, Pujol JL, Radal M, et al. In situ evaluation of growth fraction determined by monoclonal antibody $\mathrm{Ki}-67$ and ploidy in surgically resected non-small cell lung cancers. Cancer Res 1990;50:4382-7.

19 Pujol JL, Simony J, Jolimoy G, et al. Hypodiploidy, Ki-67 growth fraction and prognosis of surgically resected lung cancers. Br 7 Cancer 1996;74: and prognc

20 Coulson PB, Thornthwaite JT, Woolley TW, et al. Prognostic indicators including DNA histogram type, receptor content, and staging related to human breast cancer patient survival. Cancer Res 1984;44:4187-96.

21 Prescher G, Bornfeld N, Hirche H, et al. Prognostic implications of monosomy 3 in uveal melanoma. Lancet 1996;347:1222-5.
22 Sisley K, Rennie IG, Parsons MA, et al. Abnormalities of chromosome 3 and 8 in posterior uveal melanoma correlate with prognosis. Genes Chromosomes 8 in posterior uveal $\mathrm{m}$

23 Shackney SE, Burholt DR, Pollice AA, et al. Discrepancies between flow cytrometric and cytogenetic studies in the detection of aneuploidy in human solid tumors. Cytometry 1990;11:94-104.

24 Alers JC, van Dekken H. Interphase cytogenetic analysis of solid tumors by non-isotopic DNA in situ hybridization. Progr Histochem Cytochem Series 1996;31:1-137.

25 McNamara M, Felix C, Davison EV, et al. Assessment of chromosome 3 copy number in ocular melanoma using fluorescence in situ hybridization. Cancer Genet Cytogenet 1997;98:4-8.

26 Ghazvini S, Char DH, Kroll S, et al. Comparative genomic hybridization analysis of archival formalin-fixed paraffin-embedded uveal melanomas. Cancer Genet Cytogenet 1996;90:95-101.

\section{Contributors please note:}

Communications from the UK, Republic of Ireland, Australasia, Asia, Africa, Japan, and the Middle East should be sent to the Editor, British Journal of Ophthalmology, Department of Ophthalmology, University of Aberdeen, Medical School, Foresterhill, Aberdeen AB25 2ZD, Scotland, UK (Tel: 01224 663812; Fax: 01224 663832).

Communications from Western Europe, Eastern Europe, the former Soviet Union, and Scandinavia should be sent to Professor A Kijlstra, Associate editor, The Netherlands Ophthalmic Research Institute, PO Box 12141, Meibergdreef 9, 1100 AC Amsterdam, Netherlands (Tel: +31 20 5664535; Fax: +31 20 6913401).

Communications from the USA, Canada, and South America should be sent to Professor C Hoyt, Associate editor, University of California, UCSF Ophthalmology Department, Pediatric Ophthalmology, 400 Parnassus Avenue, Room 702 A, Box 0344, San Francisco, CA 94143, USA (Tel: +415 476 1289/1921; Fax: +415 502 6468). 